(bu nedir anlayamadim, yüzde ise parantez içinde yazalim). FVC mean value is $4.06 \pm 0.88$; FVC (\%) mean value is 90.22 \pm 16.27 . Results of FEV1/FVC mean value is $80.98 \pm 9.34$. According to ILO classification, $2.7 \%(n=3)$ of them is category $0,42.3 \%(n=47)$ is category $1 ; 28.8 \%(n=32)$ is category $2 \%$ and $26.1 \%(n=29)$ is category 3 . Five out of 10 cases $(50.0 \%)$ with radiological major opacity are type $\mathrm{A}$, the remaining five is type $\mathrm{B}$.

Conclusion Silicosis is a preventable occupational disease, but it can be incurable at later stages which might lead to respiratory failure and death. The most common symptom of silicosis is exertional dyspnea. The duration of symptoms is 2 years. Category 3 and major opacities are seen at advanced stages and indicate a belayed diagnosis. We believe that taking preventive measures for risky workers such as dental technicians, monitoring in terms of disease development and providing early diagnosis is important in combating silicosis and its complications.

\section{OCCUPATIONAL EXPOSURE TO TRICHLORAMINE AND TRIHALOMETHANES ADVERSE HEALTH EFFECTS IN REHABILITATION SWIMMING POOLS}

Jessica Westerlund*, Ing-Liss Bryngelsson, Håkan Westberg, Håkan Löfstedt, Pål Graff. Department of Occupational and Environmental Medicine, Örebro University Hospital, Örebro Sweden

\subsection{6/oemed-2018-ICOHabstracts. 1283}

Introduction Studies have shown that employees and visitors at indoor swimming pool facilities are experiencing symptoms in the nose and throat, eye irritation and, in some cases, asthma. Due to chlorination, byproduct such as trichloramine and trihalomethanes can be present in indoor swimming pool air. This exposure has not been described in rehabilitation swimming pools that normally consists of smaller facilities and use warmer water compared to ordinary swimming pools.

Methods The occupational exposure of trichloramine and trihalomethanes in air has been studied at ten Swedish indoor swimming pool facilities. The study has also included the prevalence of ocular symptoms and symptoms and effects on the upper and lower respiratory tract. Nitrogen oxide (NO) in exhaled air has been investigated as a measure of early respiratory tract inflammation.

Results The average trichloramine concentration for personal measurements $(\mathrm{n}=17)$ was $23 \mu \mathrm{g} / \mathrm{m}^{3}$, varying between 1 and $76 \mu \mathrm{g} / \mathrm{m}^{3}$. Corresponding stationary measurements $(\mathrm{n}=27)$ performed at the pool side showed an average concentration of $30 \mu \mathrm{g} / \mathrm{m}^{3}$, varying between 1 and $140 \mu \mathrm{g} / \mathrm{m}^{3}$. A WHO reference value for trichloramine, based on stationary measurements, is set to $500 \mu \mathrm{g} / \mathrm{m}^{3}$. The levels of trihalomethanes for both personal $(n=20)$ and stationary $(n=35)$ measurements were less than $1 \%$ of the Swedish OEL for chloroform. Measurements of $\mathrm{NO}$ in exhaled air showed a change during shift when exposed $(n=23)$ and controls $(n=50)$ were compared.

Discussion Both personal and stationary measurements showed low levels of trichloramine and trihalomethanes. When comparing exposed and controls during shift, a difference of NO in exhaled air was noted.

\section{RARB GENE-POLYCYCLIC AROMATIC HYDROCARBONS INTERACTION EFFECT ON PULMONARY FUNCTION DECLINE AMONG COKE OVEN WORKERS}

${ }^{1}$ Xiulong $\mathrm{Wu}^{*}$, 'Suhan Wang, 'Y Yansen Bai, ' $\mathrm{Qifei}$ Deng, 'Zhuowang Chen, ${ }^{1}$ Xiaoliang Li, ${ }^{1}$ Wenshan Fu, ${ }^{2}$ Wangzhen Zhang, ${ }^{1}$ Xiaomin Zhang, ${ }^{1}$ Meian He, ${ }^{1}$ Tangchun $\mathrm{Wu}$ ${ }^{1}$ Huan Guo. 'Department of Occupational and Environmental Health, Tongji Medical College, Wuhan, China; ${ }^{2}$ Institute of Industrial Health, Wuhan Iron and Steel (group) Corporation, Wuhan, China

\subsection{6/oemed-2018-ICOHabstracts. 1284}

Introduction Accumulating evidence indicates that gene and air pollution are associated with pulmonary function measurements. However, gene-air pollution interaction effect on pulmonary function decline remains largely unknown.

Methods A total of 1243 coke oven workers, followed up from October 2010 to October 2014, were included in the present study. Eighty-three pulmonary function strongly associated SNPs were included in the analysis. Total polycyclic aromatic hydrocarbons ( $\mathrm{OH}-\mathrm{PAHs}$ ) were determined in baseline urinary sample. Pulmonary function, forced expiratory volume in one second/forced vital capacity $\left(\mathrm{FEV}_{1} / \mathrm{FVC}\right)$ and forced expiratory flow between $25 \%$ and $75 \%$ of vital capacity $\left(\mathrm{FEF}_{25-75}\right)$, was measured in 2010 and 2014 by spirometry. The decline meant that the values of pulmonary function parameters in 2010 minus the corresponding values in 2014. Multivariate linear regression model was used to evaluate gene- $\mathrm{\Sigma OH}-\mathrm{PAHs}$ interaction effect on pulmonary function decline.

Result For RARB rs1529672, each A allele increase was associated with 0.87 (95\% CI: $0.02,1.73 ; \mathrm{p}=0.045) \%$ increased decline in $\mathrm{FEV}_{1} / \mathrm{FVC}$. When considering interaction of RARB rs1529672 with $\Sigma$ OH-PAHs on pulmonary function decline, $\Sigma \mathrm{OH}-\mathrm{PAH}$ s was not significantly associated with $\mathrm{FEV}_{1} / \mathrm{FVC}$ decline in CC carrier $[\beta(95 \% \mathrm{CI})=-0.55(-3.80,2.70)]$, but each 10 -fold increase in $\Sigma \mathrm{OH}-\mathrm{PAH}$ was related to $3.85(95 \%$ CI: $1.01,6.69)$, and 9.44 (95\% CI: 4.01, 14.87)\% increased decline in $\mathrm{FEV}_{1} / \mathrm{FVC}$ in $\mathrm{AC}$, and $\mathrm{AA}$ carrier, respectively $(P$ for interaction=0.0006). Similar results appeared for RARB rs1529672 and gene- $\Sigma \mathrm{OH}-\mathrm{PAH}$ interaction effect on $\mathrm{FEF}_{25-75}$ decline.

Conclusion Our findings show that minor allele carrier of RARB rs1529672 is more susceptible to $\Sigma \mathrm{OH}-\mathrm{PAHs}$ caused pulmonary function decline than major allele homozygote, and provide evidence for gene- $\Sigma \mathrm{OH}-\mathrm{PAH}$ interaction effect on pulmonary function decline.

\section{SERUM PROLIDASE ACTIVITY IN SILICOSIS}

${ }^{1}$ Türkan Nadir Öziş, ${ }^{2}$ Uğur Nadir Karakulak, ${ }^{3}$ Nur Şafak Alici, ${ }^{4}$ Yusuf Bayrakçeken, ${ }^{5}$ Ömer Hinç Yilmaz. 'Department of Chest Diseases, Ankara Occupational Disease Hospital, Ankara, Turkey; ${ }^{2}$ Department of Cardiology Ankara Occupational Disease Hospital, Ankara, Turkey; ${ }^{3}$ Department of Chest Diseases, Faculty of Medicine, Dokuz Eylul University, Izmir, Turkey; ${ }^{4}$ Departman of Medical Biology, Hacettepe University, Ankara, Turkey; ${ }^{5}$ Ankara Occupational Disease Hospital, Ankara, Turkey

\subsection{6/oemed-2018-ICOHabstracts. 1285}

Introduction Silicosis is the result of silica exposure. Many chemotactic mediators arise with toxicity resulting from exposure to silica particles and silicotic nodules occur from the 